PAPER

\title{
Increasing unsaturated dissolved oxygen concentration in water by fine bubbles induced by ultrasonic vibrations
}

\author{
Hikaru Miura*, Masayuki Nakada and Takuya Asami ${ }^{\dagger}$ \\ Department of Electrical Engineering, College of Science and Technology, Nihon University, \\ 1-8-14 Kanda-surugadai, Chiyoda-ku, Tokyo, 101-8308 Japan
}

(Received 10 June 2014, Accepted for publication 9 January 2015)

\begin{abstract}
In the past, much research has centered on dispersing liquids into gases, and dispersing solids and liquids into liquids. However, there has been almost no research on dissolving gases into liquids by dispersion, possibly because of concerns about the effect of deaeration due to cavitation of a liquid by ultrasound. Here, we consider a method using ultrasound to finely disperse and dissolve a supplied gas. The method entails placing the gas supply outlet close to the tip of an ultrasonic longitudinal vibration source and dissolving the gas into the liquid by finely dispersing the gas by means of the vibrations. In this method, the occurrence of cavitation is reduced as much as possible and deaeration effects are reduced. Here, air is used as the gas to be dissolved and water is used as the solvent. The unsaturated dissolved oxygen concentration in water is used as an indicator for evaluating the proportion of dissolved air. The results show that ultrasonic vibration increases the concentration of oxygen dissolved in the liquid and that almost no deaeration by cavitation occurs.
\end{abstract}

Keywords: Ultrasonic vibration, Fine bubbles, Air bubble generation, Dissolved oxygen, Dissolved gas

PACS number: 43.35.-c, 43.35.Ty [doi:10.1250/ast.36.240]

\section{INTRODUCTION}

One action of ultrasound is dispersion. In the past, much research has centered on dispersing liquids into gases, and dispersing solids and liquids into liquids [1-9]. However, there has been almost no research on dissolving gases into liquids by dispersion, possibly because of concerns about the effect of deaeration due to cavitation of a liquid by ultrasound [10-14]. One method for dissolving a gas in a liquid is to promote dissolution by increasing the surface area of the gas by finely dispersing it throughout the liquid. The main examples of this method are the pressurized dissolution method and the swirling liquid flow method. However, since these methods require the liquid to flow, they require elaborate equipment with moving parts, making it difficult to dissolve gas into small quantities of liquids [15,16].

One example of a method of finely dispersing gas by ultrasound was proposed by Makuta et al. [17,18]. This method focuses on the generation of fine bubbles and is capable of finely dispersing the gas into particles of

*e-mail: miura.hikaru@nihon-u.ac.jp

†e-mail: asami.takuya@nihon-u.ac.jp uniform size because it makes use of the resonance of the air-liquid boundary to achieve fine dispersion. However, this method is readily affected by water pressure, and achieving fine dispersion is considered to be problematic if, for example, the water depth changes.

Here, we consider a method for finely dispersing and dissolving a supplied gas without using liquid flow and the fine dispersion unit is not affected by water depth. The method entails placing the output that supplies the gas to be dissolved extremely close to the tip of an ultrasonic longitudinal vibration source and dissolving the gas into the liquid by finely dispersing the gas by means of vibrations [19]. In this method, the occurrence of cavitation is reduced as much as possible, and deaeration effects are reduced by placing the ultrasonic longitudinal vibration source and gas supply outlet next to each other.

In this study, we performed a basic investigation of dissolving gas by fine dispersion using ultrasonic vibrations. In this method, fine dispersion increases the mass transfer rate and reduces the time to reach saturation [20-22]. Air was used as the gas to be dissolved and water was used as the solvent. The unsaturated dissolved oxygen concentration in the solvent was used as an indicator for evaluating the proportion of dissolved air. In this inves- 


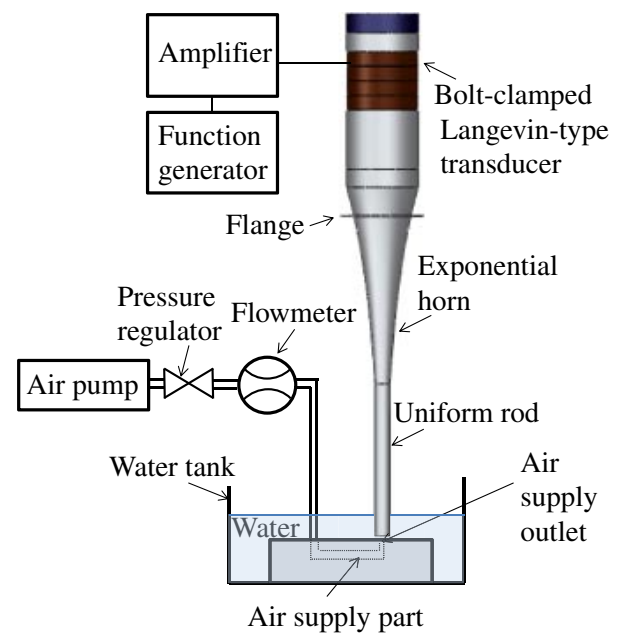

(a) Entire apparatus.

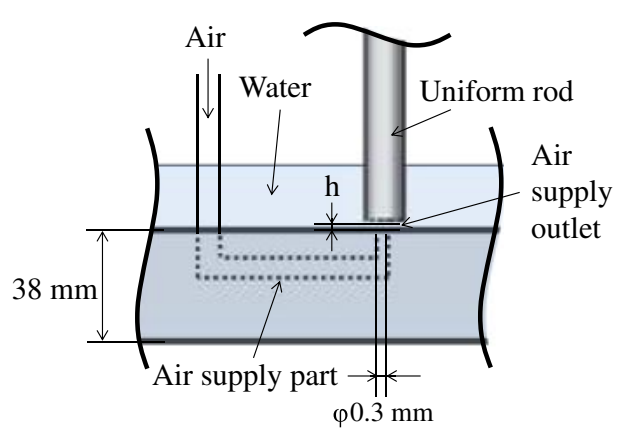

(b) Air supply outlet.

Fig. 1 Overview schematic of the gas fine-bubbling apparatus.

tigation, all of the dissolved oxygen concentrations are in the unsaturated state. We investigated (1) the increase in unsaturated dissolved oxygen concentration upon fine dispersion of air, and the increase in unsaturated dissolved oxygen concentration upon fine dispersion of air in response to varying (2) the input power, (3) the flow rate of the supplied gas, (4) the amount of water in the tank, and (5) the vertical distance between the air supply outlet and the ultrasonic vibration source tip. These investigations revealed the advantages of dissolving gas by ultrasonic irradiation.

\section{APPARATUS AND METHOD}

\subsection{Apparatus}

Figure 1 shows an overview of the fine gas dispersion apparatus. Figure 1(a) shows a schematic of the entire apparatus, while Fig. 1(b) shows only the air supply outlet. As shown in Fig. 1(a), the apparatus consists of an ultrasonic longitudinal vibration source, water tank, and air supply outlet. The ultrasonic longitudinal vibration source consists of an exponential horn (amplitude magnification ratio, 4.6) made of duralumin attached to a $20 \mathrm{kHz}$ bolt-clamped Langevin-type transducer with a uniform rod (diameter, $12 \mathrm{~mm}$; length, $120 \mathrm{~mm}$ ) made of duralumin and attached to the tip. The tip of the ultrasonic longitudinal vibration source is inserted into the water from the top of the water tank pointing down ward. The water tank is an acrylic rectangular parallelepiped $145 \mathrm{~mm}$ long, $145 \mathrm{~mm}$ wide, and $200 \mathrm{~mm}$ deep. Air is fed to the air supply outlet from a pump (NUP-2) with a gas pressure rating of $200 \mathrm{kPa}$, the gas pressure being regulated by a pressure regulator (IR-1B). The airflow rate after regulation is measured using a flow meter (SEF-21A). The air fed from the pressure regulator is emitted from the air supply outlet (diameter, $0.3 \mathrm{~mm}$ ) onto the ultrasonic longitudinal vibration source tip.

\subsection{Method}

Experiments were performed at standard temperature and pressure. The gas was finely dispersed by supplying air with simultaneous ultrasonic irradiation using the apparatus shown in Fig. 1. The drive frequency of the ultrasonic longitudinal vibration source was fixed at $19.4 \mathrm{kHz}$, which was the longitudinal vibration resonant frequency of the vibration source. The position of the ultrasonic vibration source tip was arranged such that the air supply outlet was beneath and at the center of the vibration plane. The water tank was filled with tap water that had been heated to almost fully deaerate the water and returned to standard temperature. Throughout the experiments, the water was maintained at a constant temperature of $25 \pm 1^{\circ} \mathrm{C}$. The water was replaced after each experiment. The saturated dissolved oxygen concentration in water at $25^{\circ} \mathrm{C}$ is 8.1 $\mathrm{mg} / \mathrm{l}$. A dissolved oxygen concentration meter (Mettler Toledo, SG6) was used to measure the concentration of oxygen dissolved in the water. The measurement location was at a position $10 \mathrm{~mm}$ above the bottom of the water tank in all measurements.

From the results of simulation by the finite-element method (COMSOL Multiphysics), the magnitude of pressure in the water tank is approximately one-seventh that in the uniform rod and air supply outlet.

\section{OBSERVATION OF FINE DISPERSION OF AIR}

Observations were made to compare the states of fine dispersion of air in the water with and without of ultrasonic irradiation by arranging the apparatus such that the vertical distance $h$ between the air supply outlet and the uniform rod tip of the ultrasonic vibration source was constant $(0.5 \mathrm{~mm})$. The water tank was filled with $1 l$ of water (water depth, $58 \mathrm{~mm}$ ), the input power supplied to the ultrasonic vibration source was fixed at $20 \mathrm{~W}$ (longitudinal vibration amplitude, approx. $20 \mu \mathrm{m}_{\mathrm{p}-\mathrm{p}}$ ), and the supplied airflow rate was fixed at $0.5 \mathrm{l} / \mathrm{min}$. Observations were made both for the case where air was supplied without ultrasonic irradiation and for the case where air was supplied with 


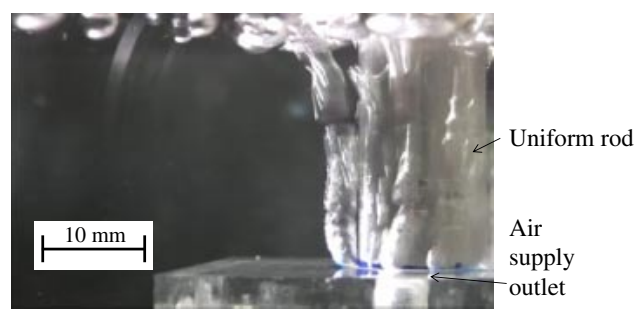

(a) Without ultrasonic irradiation.

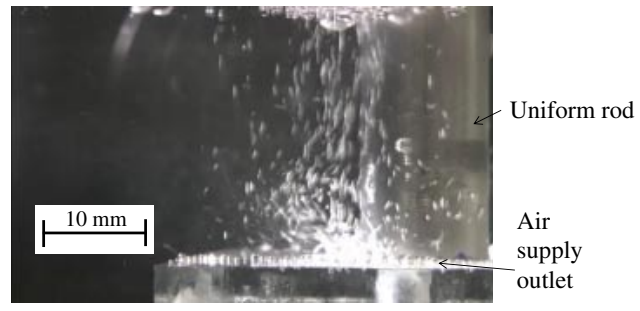

(b) With ultrasonic irradiation.

Fig. 2 Fine dispersion of air (exposure time, 1/30s).

ultrasonic irradiation. Figure 2(a) shows the state with air supply only; bubbles with diameters of millimeter order were observed. Figure 2(b) shows the state with air supply and ultrasonic irradiation; bubble diameters were clearly smaller than the case without irradiation. In this study, fine dispersion is defined as the state shown in Fig. 2(b), where bubbles of small diameter were generated.

\section{UNSATURATED DISSOLVED OXYGEN CONCENTRATION WITH FINELY DISPERSED AIR}

\subsection{Increase in Unsaturated Dissolved Oxygen Con- centration by Finely Dispersed Air}

It is clear that the ultrasonic vibrations finely dispersed the supplied air. We thus investigated the unsaturated dissolved oxygen concentration in the water with and without supplied air and ultrasonic irradiation. Measurements were performed with the water tank filled with $1 l$ of water, the air supply outlet positioned at a water depth of $20.5 \mathrm{~mm}$, the input power supplied to the ultrasonic vibration source fixed at $20 \mathrm{~W}$, the vertical distance $h$ between the air supply outlet and uniform rod tip of the ultrasonic vibration source fixed at $0.5 \mathrm{~mm}$, and the flow rate of the supplied air fixed at $0.5 \mathrm{l} / \mathrm{min}$. The unsaturated dissolved oxygen concentration was measured 10 times for each of the following 4 cases: without both ultrasonic irradiation and without air supply, with ultrasonic irradiation only, with air supply only, and with both air supply and ultrasonic irradiation. The results are shown in Fig. 3, with elapsed time on the horizontal axis and unsaturated dissolved oxygen concentration on the vertical axis. Ultrasonic irradiation and air supply were performed for $5 \mathrm{~min}$ from 22 to $27 \mathrm{~min}$ such that the unsaturated dissolved

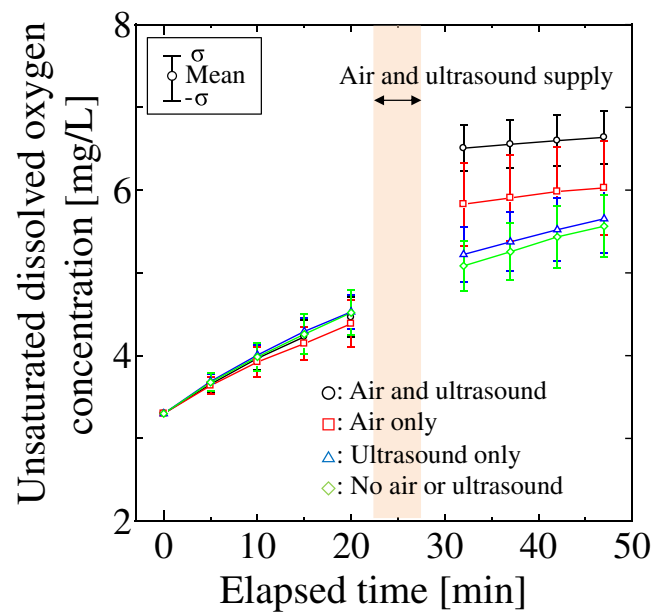

Fig. 3 Time variation of unsaturated dissolved oxygen concentration (amount of water in tank, $1 l$; input power, $20 \mathrm{~W}$; airflow rate, $0.5 \mathrm{l} / \mathrm{min}$; distance $h$, $0.5 \mathrm{~mm}$; water temperature, $25 \pm 1^{\circ} \mathrm{C}$ ).

oxygen would not saturate while air was being supplied, with no ultrasonic irradiation or air supply before or after this period. Plots show mean values, with the standard deviation $\sigma$ indicated by the upper and lower error bars.

The unsaturated dissolved oxygen concentration increased with time from 0 to $20 \mathrm{~min}$ despite the lack of ultrasonic irradiation and air supply, possibly because the water surface was always in contact with the atmosphere and because air dissolved into the water from the water surface. Furthermore, the increase in unsaturated dissolved oxygen concentration from 32 to $47 \mathrm{~min}$, when air was not supplied, showed almost the same trend regardless of the presence or absence of ultrasonic irradiation. Thus, in this method, ultrasonic irradiation caused almost no deaeration of the dissolved oxygen, possibly because the tip of the ultrasonic vibration source had almost no contact with the water in the tank since it was placed extremely close to the air supply outlet. In other words, almost no deaeration occurred because no high acoustic pressure propagated into the water tank. Next, it is clear that the supply of air with ultrasonic irradiation greatly increased the concentration of oxygen dissolved in the water from 22 to $27 \mathrm{~min}$. This shows that the unsaturated dissolved oxygen concentration increases even more than in the case of only supplying air for $5 \mathrm{~min}$ from 22 to $27 \mathrm{~min}$. Furthermore, the unsaturated dissolved oxygen concentration when air was not supplied showed the same trend regardless of the presence or absence of ultrasonic irradiation. This indicates that here is almost no deaeration effect, as described above. The unsaturated dissolved oxygen concentrations at 20 and 32 min were then compared. Table 1 shows the increase in unsaturated dissolved oxygen concentration before and after applying the ultrasonic irradiation and air supply in each of the cases. The increase in unsaturated dissolved 
Table 1 Increase in unsaturated dissolved oxygen concentration.

\begin{tabular}{|c|c|c|c|}
\hline \multirow{2}{*}{\multicolumn{2}{|c|}{$\begin{array}{l}\text { Increase in unsaturated } \\
\text { dissolved oxygen concentration } \\
\text { (standard deviation } \sigma) \\
{[\mathrm{mg} / l]}\end{array}$}} & \multicolumn{2}{|c|}{ Input power } \\
\hline & & $0 \mathrm{~W}$ & $20 \mathrm{~W}$ \\
\hline \multirow{2}{*}{ Airflow rate } & $0 l / \min$ & $\begin{array}{c}0.57 \\
(0.05)\end{array}$ & $\begin{array}{c}0.69 \\
(0.16)\end{array}$ \\
\hline & $0.5 \mathrm{l} / \mathrm{min}$ & $\begin{array}{c}1.44 \\
(0.26)\end{array}$ & $\begin{array}{c}2.04 \\
(0.09)\end{array}$ \\
\hline
\end{tabular}

oxygen concentration was nearly the same, regardless of the presence or absence of ultrasonic irradiation when no air was supplied. However, it is clear that the increase in unsaturated dissolved oxygen concentration when air was supplied with ultrasonic irradiation was approximately 1.4-fold higher than that without ultrasonic irradiation. This shows that fine dispersion of air with ultrasonic irradiation can promote oxygen dissolution.

The changes in unsaturated dissolved oxygen concentration from 0 to $20 \mathrm{~min}$ and 32 to $47 \mathrm{~min}$ were attributed solely to the water surface being in contact with the atmosphere in all cases. In the subsequent investigations, we thus compared and investigated the increase in unsaturated dissolved oxygen concentration between before ( 0 to $20 \mathrm{~min}$ ) and after ( 32 to $47 \mathrm{~min}$ ) supplying air with ultrasonic irradiation.

\subsection{Increase in Unsaturated Dissolved Oxygen Con- centration with Varying Power Supply}

We investigated the increase in unsaturated dissolved oxygen concentration upon fine dispersion of air with varying power supplied to the ultrasonic vibration source. The unsaturated dissolved oxygen concentration was measured 10 times in each case while the power of the ultrasonic irradiation was varied from 0 to $60 \mathrm{~W}$ for $5 \mathrm{~min}$. The water tank was filled with $1 l$ of water, and the vertical distance $h$ between the air supply outlet and the uniform rod tip of the ultrasonic vibration source was fixed at $0.5 \mathrm{~mm}$ and the flow rate of the supplied air was fixed at $0.5 \mathrm{l} / \mathrm{min}$. The experiments were performed using unsaturated dissolved oxygen concentrations in the range of $3-6 \mathrm{mg} / \mathrm{l}$ before ultrasonic irradiation and air supply. Although it is desirable for this concentration to be a fixed value, some variation occurred depending on the state of the experimental apparatus. The experimental results thus show the trend within this initial concentration range. The results are shown in Fig. 4, with the power supplied to the ultrasonic vibration source on the horizontal axis and the increase in unsaturated dissolved oxygen concentration on the vertical axis. A clear trend that the unsaturated

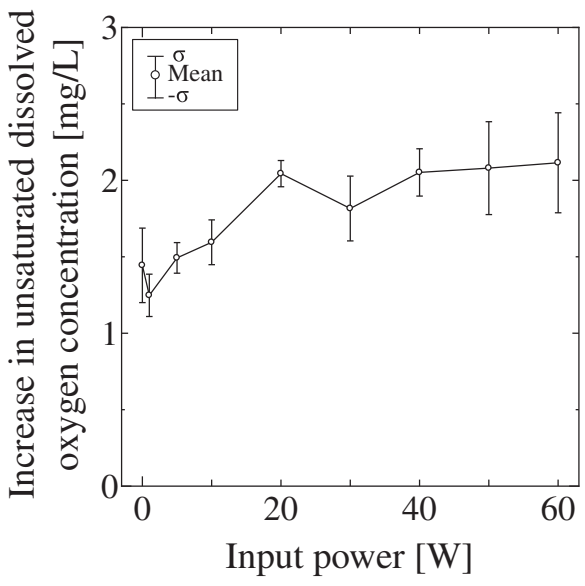

Fig. 4 Increase in unsaturated dissolved oxygen concentration with increased power supply (amount of water in tank, $1 l$; airflow rate, $0.5 \mathrm{l} / \mathrm{min}$; distance $h$, $0.5 \mathrm{~mm}$; water temperature, $25 \pm 1^{\circ} \mathrm{C}$ ).

dissolved oxygen concentration increases and becomes a constant value as the supplied power is increased is evident.

Even when a state of fine dispersion of air was observed for a small amount of supplied power, large bubbles that had not been finely dispersed were also observed. Increasing the power resulted in more pronounced fine dispersion and decreased the number of large bubbles. Furthermore, almost no large bubbles were observed at a power of $20 \mathrm{~W}$ or higher. This shows that the unsaturated dissolved oxygen concentration increased with the amount of finely dispersed bubbles generated. Since the concentration of oxygen dissolved in the water becomes a constant value at an input power of $20 \mathrm{~W}$ and higher, fine dispersion of air was not considered to be promoted by using such a high power. The input power of the vibration source was fixed at $20 \mathrm{~W}$ in the remaining experiments.

\subsection{Increase in Unsaturated Dissolved Oxygen Con- centration with Varying Airflow Rate}

We investigated the increase in unsaturated dissolved oxygen concentration upon fine dispersion of air with varying flow rate from the air supply outlet. The concentration of dissolved water was measured 10 times in each case with the flow rate being varied from 0 to $0.75 \mathrm{l} / \mathrm{min}$ in the presence and absence of ultrasonic irradiation. The water tank was filled with $1 l$ of water, and the vertical distance $h$ between the air supply outlet and the uniform rod tip of the ultrasonic vibration source was fixed at $0.5 \mathrm{~mm}$ and the input power supplied to the ultrasonic vibration source was fixed at $20 \mathrm{~W}$. The experiments were performed using unsaturated dissolved oxygen concentrations in the range of $3-6 \mathrm{mg} / \mathrm{l}$ before ultrasonic irradiation 


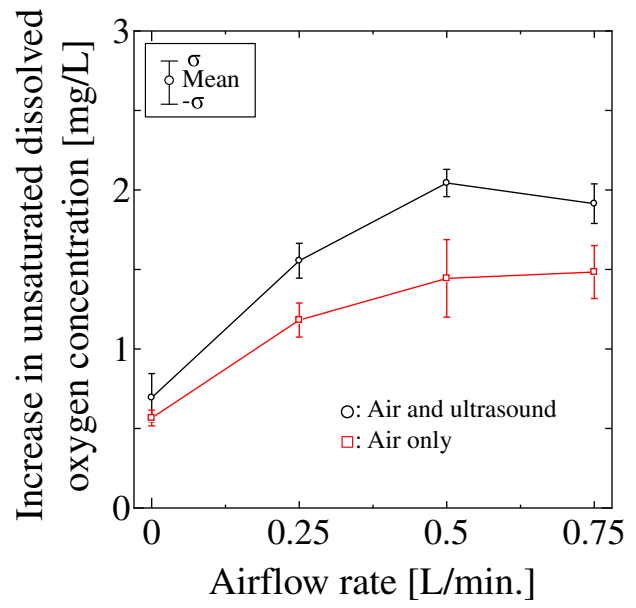

Fig. 5 Increase in unsaturated dissolved oxygen concentration with increased airflow rate (amount of water in tank, $1 l$; input power, $20 \mathrm{~W}$; distance $h, 0.5 \mathrm{~mm}$; water temperature, $25 \pm 1^{\circ} \mathrm{C}$ ).

and air supply. Furthermore, ultrasonic irradiation and air supply were performed for $5 \mathrm{~min}$.

The results are shown in Fig. 5, with the flow rate of the air supplied to the outlet on the horizontal axis and the increase in unsaturated dissolved oxygen concentration on the vertical axis. The concentration of oxygen dissolved in the water showed an increasing trend with the flow rate and then became a constant value as the flow rate was increased further, regardless of the presence or absence of ultrasonic irradiation. Furthermore, the increase in unsaturated dissolved oxygen concentration was clearly larger when ultrasonic irradiation was performed than when it was not.

When fine dispersion of air was observed, the amount of finely dispersed air spreading through the water tank was observed to increase with the flow rate. From this, the increase in the concentration of oxygen dissolved in the water is attributed to the increase in the amount of finely dispersed air owing to the increased amount of supplied air.

\subsection{Increase in Unsaturated Dissolved Oxygen Con- centration with Varying Amount of Water in the Tank}

We investigated the increase in unsaturated dissolved oxygen concentration upon fine dispersion of air with varying amount of water in the tank. The concentration of dissolved water was measured 10 times in each case and the amount of water in the tank was varied from 0.7 to $3 l$ (since the area of the base of the water tank was constant, this corresponds to a depth of 8 to $121 \mathrm{~mm}$ above the air supply outlet) with neither ultrasonic irradiation nor air supply and with both ultrasonic irradiation and air supply. The vertical distance $h$ between the air supply outlet and the uniform rod tip of the ultrasonic vibration source was fixed at $0.5 \mathrm{~mm}$, the input power supplied to the ultrasonic

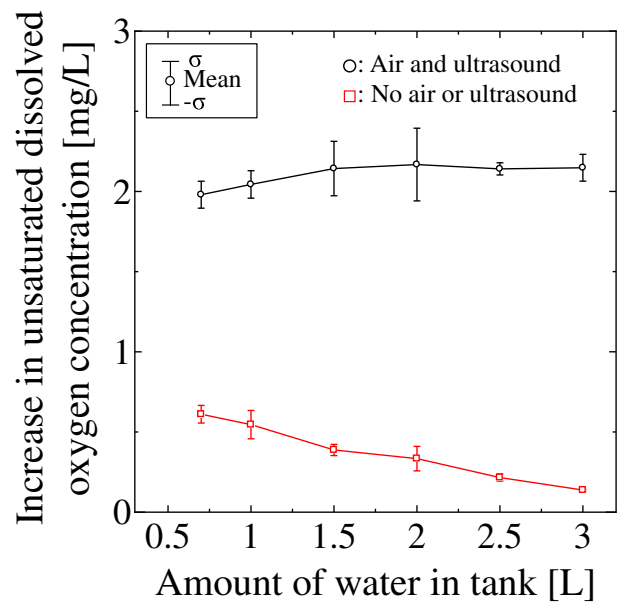

Fig. 6 Increase in unsaturated dissolved oxygen concentration with an increase in the amount of water in the tank (input power, $20 \mathrm{~W}$; airflow rate, $0.5 \mathrm{l} / \mathrm{min}$; distance $h, 0.5 \mathrm{~mm}$; water temperature, $25 \pm 1^{\circ} \mathrm{C}$ ).

vibration source was fixed at $20 \mathrm{~W}$, and the flow rate of the supplied air was fixed at $0.5 \mathrm{l} / \mathrm{min}$. The experiments were performed using unsaturated dissolved oxygen concentrations in the range of $3-6 \mathrm{mg} / l$ before ultrasonic irradiation and air supply. Furthermore, ultrasonic irradiation and air supply were performed for $5 \mathrm{~min}$.

The results are shown in Fig. 6, with the amount of water in the tank shown on the horizontal axis and the increase in unsaturated dissolved oxygen concentration shown on the vertical axis. It is clear that the increase in unsaturated dissolved oxygen concentration when no ultrasonic irradiation or air is supplied decreases as more water is added, possibly because the contact area between the water surface and air remains constant as the amount of water in the tank is varied, and since the absolute amount of air dissolving from the atmosphere remains constant, the amount of oxygen dissolved per unit volume decreases with increasing amount of water in the tank. However, when ultrasonic irradiation and air supply were performed, although the increase in unsaturated dissolved oxygen concentration was found to increase, to some degree, as the amount of water increased to a maximum of $1.5 \mathrm{l}$, it remained almost constant when the amount of water exceeded $1.5 \mathrm{l}$. This indicates that the absolute amount of oxygen dissolved in the water increases with increasing amount of water. Furthermore, when fine dispersion of air was observed, no variation in the way that fine bubbles were generated could be seen as the amount of water in the tank was increased. The vibration source tip was not very deep in the water, so the effect of increasing water pressure on acoustic pressure is considered to be negligible. These results show that the fine dispersion of gas is not affected by some degree of variation in water depth in the case of the gas can dissolve into the liquid. 


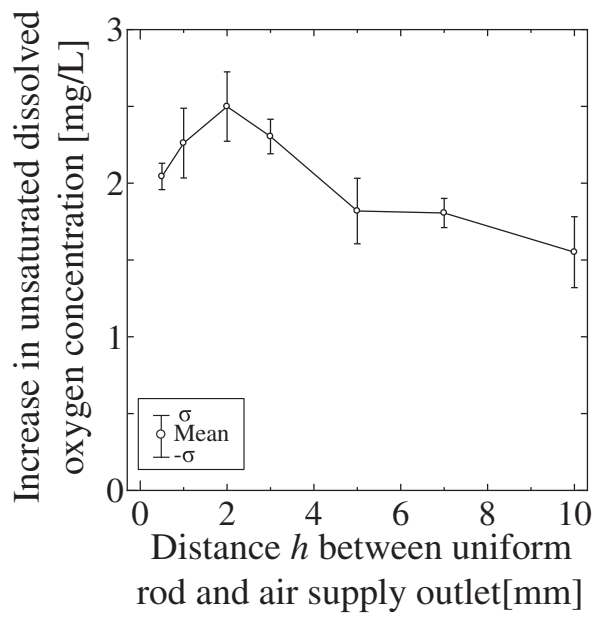

Fig. 7 Increase in unsaturated dissolved oxygen concentration with varying distance between air supply outlet and uniform rod tip (amount of water in tank, 1 ; input power, $20 \mathrm{~W}$; airflow rate, $0.5 \mathrm{l} / \mathrm{min}$; water temperature, $25 \pm 1^{\circ} \mathrm{C}$ ).

\subsection{Increase in Unsaturated Dissolved Oxygen Con- centration with Varying Vertical Distance Be- tween the Air Supply Outlet and Ultrasonic Vibration Source Tip}

We investigated the increase in unsaturated dissolved oxygen concentration upon fine dispersion of air with varying vertical distance $h$ between the air supply outlet and the uniform rod tip of the ultrasonic vibration source. The concentration of dissolved water was measured 10 times in each case with $h$ being varied from 0.5 to $10 \mathrm{~mm}$. The water tank was filled with $1 l$ of water, the input power supplied to the ultrasonic vibration source was fixed at $20 \mathrm{~W}$, and the flow rate of the supplied air was fixed at $0.5 \mathrm{l} / \mathrm{min}$. The experiments were performed using unsaturated dissolved oxygen concentrations in the range of $4-5.5 \mathrm{mg} / \mathrm{l}$ before ultrasonic irradiation and air supply. Furthermore, ultrasonic irradiation and air supply were performed for $5 \mathrm{~min}$. The results are shown in Fig. 7, with the vertical distance $h$ between the air supply outlet and the uniform rod tip of the ultrasonic vibration source on the horizontal axis and the increase in unsaturated dissolved oxygen concentration on the vertical axis. It is clear that the dissolved oxygen concentration when air supply and ultrasonic irradiation were performed became maximum when $h$ was $2 \mathrm{~mm}$. This result implies an optimal distance between the uniform rod tip of the ultrasonic vibration source and the air supply outlet for increasing the unsaturated dissolved oxygen concentration by fine bubbling.

Figure 8 shows the fine dispersion of air at each $h$ value. Figure 8(a) shows the case where the vertical distance $h$ between the air supply outlet and the uniform rod tip of the ultrasonic vibration source was $0.5 \mathrm{~mm}$. It is

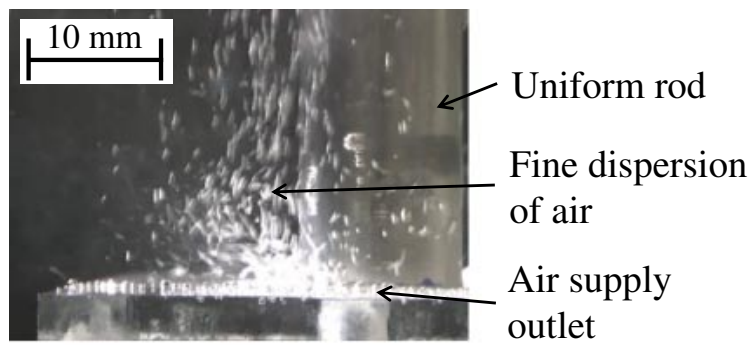

(a) $h=0.5 \mathrm{~mm}$.

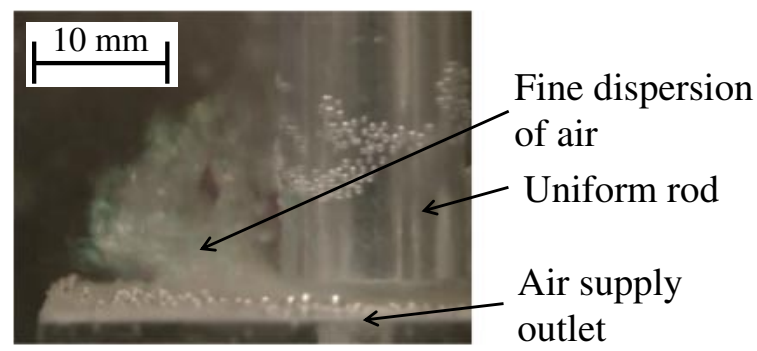

(b) $h=2.0 \mathrm{~mm}$.

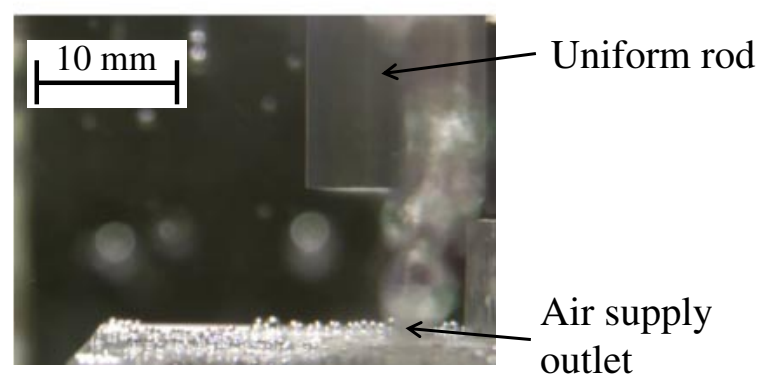

(c) $h=10.0 \mathrm{~mm}$.

Fig. 8 State of the fine dispersion of air with changing distance between air supply outlet and uniform rod tip (exposure time, $1 / 30 \mathrm{~s}$ ).

clear that the finely dispersed air does not readily disperse into the surroundings, but remains near the uniform rod. Figure 8(b) shows the case where the distance $h$ is $2 \mathrm{~mm}$. The area with a cloudlike appearance on the left side of the uniform rod is finely dispersed air. A phenomenon that the finely dispersed air was dispersed within the tank with good momentum was observed, possibly because $2 \mathrm{~mm}$ is the optimal $h$ for readily dispersing air into the surroundings. Furthermore, it is clear that the particles of finely dispersed air are smaller than those when $h=0.5 \mathrm{~mm}$. Figure 8(c) shows the case where the distance $h$ is $10 \mathrm{~mm}$. At this distance, fine bubbling is almost undetectable visually as the air does not come into contact with the vibrating plane. It is likely that fine dispersion of the supplied air does not readily occur with ultrasonic irradiation when the distance is too far.

\section{DISCUSSION}

The unsaturated dissolved oxygen concentration was increased most effectively when fine dispersion of air was 
produced with both ultrasonic irradiation and air supply, thereby demonstrating gas dissolution by ultrasonic irradiation. Furthermore, deaeration effects were reduced by setting the air supply outlet at a position extremely close to the ultrasonic longitudinal vibration source tip. In other words, acoustic pressure effects could be reduced in the area surrounding the air supply unit.

(a) When the input power to the ultrasonic vibration source was varied, the increase in unsaturated dissolved oxygen concentration upon fine dispersion of air increased as more power was supplied to the ultrasonic vibration source, and it became a constant value at $>20 \mathrm{~W}$. This was likely due to the vibration source amplitude displacement and vibration acceleration increasing with the power increase, where the amount of finely dispersed bubbles increased owing to the increased energy applied to the air. In terms of fine dispersion of air, since large bubbles that had not been finely dispersed were observed when the power was low, the power needed to finely disperse all of the supplied gas is inferred to differ depending on the flow rate of the gas.

(b) When the airflow rate from the air supply outlet was varied, the increase in unsaturated dissolved oxygen concentration upon generating fine bubbles increased as the flow rate of the supplied air was increased. However, since excessively large flow rates hinder fine dispersion, a flow rate where all of the air can be finely dispersed will be optimal.

(c) When the amount of water was changed, the increase in unsaturated dissolved oxygen concentration upon generating fine bubbles remained nearly constant, and it was clear that changing the amount of water had no effect within our measurement range. Furthermore, although the water depth of the air supply outlet changed as the amount of water changed, this was also found to have almost no effect. Therefore, the unsaturated dissolved oxygen concentration is considered to be unaffected by changes in water pressure owing to changes in water depth, and the main cause of the fine dispersion of air is considered to be the ultrasonic vibrations.

(d) When the vertical distance between the air supply unit and the ultrasonic vibration source tip was changed, the increase in unsaturated dissolved oxygen concentration upon generating fine bubbles was greatest when the distance was $2 \mathrm{~mm}$. The fine dispersion of air is attributed to flow induced by acoustic streaming. Furthermore, additional fine dispersion of air is expected owing to the action of acoustic pressure. The optimal value for the distance between the horn tip and the air supply outlet is considered to depend on factors such as the size of the air supply outlet and the airflow rate, in addition to the vibration displacement, velocity, acceleration, and frequency of the horn tip. However, the effect of deaeration must also be investigated.

Taken together, since the fine dispersion of air occurs actively if the air supply outlet and ultrasonic vibration source tip are near each other, the main factors in the fine dispersion of air are aggressive fracture and fine dispersion by the air colliding with the ultrasonic vibrations from the vibration source. Fine dispersion of air is thus considered to increase the unsaturated dissolved oxygen concentration by increasing the efficiency with which the air dissolves into water.

\section{CONCLUSIONS}

We investigated the dissolution of a gas into a liquid by fine dispersion of air brought about by placing the air supply outlet extremely close to the tip of an ultrasonic longitudinal vibration source. The following results were obtained.

(a) The unsaturated dissolved oxygen concentration in the liquid was increased by performing ultrasonic irradiation while supplying air, by increasing the input power to the vibration source, and by increasing the amount of air supplied. Almost no deaeration by cavitation was observed.

(b) In this method, the main causes of the fine dispersion of air are considered to be fracturing and fine dispersion of air by colliding with ultrasonic vibrations induced by the vibration source. The effect of water pressure is thus considered to be small during fine dispersion.

Further investigations are necessary to elucidate the principles of the fine dispersion of air, the particle sizes of finely dispersed air, and the increase in the unsaturated dissolved oxygen concentration. In addition, we are planning to investigate the shapes of vibration sources that are most suitable for the fine dispersion of air.

\section{REFERENCES}

[1] R. J. Lang, "Ultrasonic atomization of liquids," J. Acoust. Soc. Am., 34, 6-8 (1962).

[2] M. Kurosawa, T. Watanabe, A. Futami and T. Higuchi, "Surface acoustic wave atomizer," Sensor Actuat. A-Phys., 50, 69-74 (1995).

[3] Y. Onishi and H. Miura, "Convergence of sound waves radiated from aerial ultrasonic source using square transverse vibrating plate with several reflective boards," Jpn. J. Appl. Phys., 44, 4682-8688 (2005).

[4] K. Yasuda, Y. Bando, S. Yamaguchi, M. Nakamura, A. Oda and Y. Kawase, "Analysis of concentration characteristics in ultrasonic atomization by droplet diameter distribution," Ultrason. Sonochem., 12, 37-41 (2005).

[5] Y. Ito, R. Kato and A. Osumi, "Examinations of behavior of liquid irradiated with high-intensity aerial ultrasonic waves in a long pore," Jpn. J. Appl. Phys., 52, 07HE12 (2013). 
[6] D. J. McClements, "Ultrasonic characterisation of emulsions and suspensions," Adv. Colloid Interface Sci., 37, 33-72 (1991).

[7] T. S. H. Leong, T. J. Wooster, S. E. Kentish and M. Ashokkumar, "Minimising oil droplet size using ultrasonic emulsification," Ultrason. Sonochem., 16, 721-727 (2009).

[8] H. Miura, M. Takata, D. Tajima and K Tsuyuki, "Promotion of methane hydrate dissociation by underwater ultrasonic wave," Jpn. J. Appl. Phys., 45, 4816-4823 (2006).

[9] W. Klaypradit and Y. W. Huang, "Fish oil encapsulation with chitosan using ultrasonic atomizer," LWT-Food Sci. Technol., 41, 1133-1139 (2008).

[10] M. Strasberg, "Onset of ultrasonic cavitation in tap water," J. Acoust. Soc. Am., 31, 163-176 (1959).

[11] L. A. Crum, "Acoustic cavitation series: Part five rectified diffusion," Ultrasonics, 22, 215-223 (1984).

[12] R. K. Khamzin, "Ultrasonic deaeration of synthetic aluminosilicate adsorbent oil," Chem. Technol. Fuels Oils, 31, 302305 (1995).

[13] O. Ayyildiz, P. R. Anderson and R. W. Peters, "Laboratory batch experiments of the combined effects of ultrasound and air stripping in removing $\mathrm{CCl}_{4}$ and 1,1,1-TCA from water," J. Hazard. Mater., B120, 149-156 (2005).

[14] N. Gondrexon, V. Renaudin, P. Boldo, Y. Gonthier, A. Bernis and C. Petrier, "Degassing effect and gas-liquid transfer in a high frequency sonochemical reactor," J. Chem. Eng., 66,
21-26 (1997).

[15] X. Gong, S. Takagi and Y. Matsumoto, "The effect of bubbleinduced liquid flow on mass transfer in bubble plumes," Int. J. Multiphase Flow, 35, 155-162 (2009).

[16] K. Terasaka, A. Hirabayashi, T. Nishino, S. Fujioka and D. Kobayashi, "Development of microbubble aerator for waste water treatment using aerobic activated sludge," Chem. Eng. Sci., 66, 3172-3179 (2011).

[17] T. Makuta, F. Takemura, E. Hihara, Y. Matsumoto and M. Shoji, "Generation of micro gas bubbles of uniform diameter in an ultrasonic field," J. Fluid Mech., 548, 113-131 (2006).

[18] T. Makuta, R. Suzuki and T. Nakao, "Generation of microbubbles from hollow cylindrical ultrasonic horn," Ultrasonics, 53, 196-202 (2013).

[19] M. Nakada, T. Asami and H. Miura, "Increase dissolved oxygen by fine bubbles using ultrasonic vibration," IEICE Tech. Rep., 113, US2013-76, pp. 13-18 (2013) (in Japanese).

[20] V. Schlijter and W. D. Deckwer, "Gas/liquid mass transfer in stirred vessels," Chem. Eng. Sci., 47, 2357-2362 (1992).

[21] A. Kumar, P. R. Gogate, A. B. Pandit, H. Delmas and A. M. Wilhelm, "Gas-liquid mass transfer studies in sonochemical reactors," Ind. Eng. Chem. Res., 43, 1812-1819 (2004).

[22] F. Laugier, C. Andriantsiferana, A. M. Wilhelm and H. Delmas, "Ultrasound in gas-liquid systems: Effects on solubility and mass transfer," Ultrason. Sonochem., 15, 965972 (2008) 